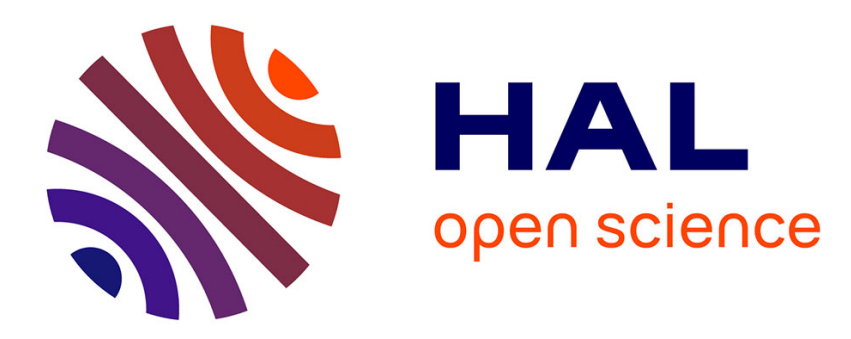

\title{
The Exploitation of Fine Phonetic Detail in the Processing of L2 French
}

Ellenor Shoemaker

\section{To cite this version:}

Ellenor Shoemaker. The Exploitation of Fine Phonetic Detail in the Processing of L2 French. 2010. halshs-00668896

\section{HAL Id: halshs-00668896 \\ https://shs.hal.science/halshs-00668896}

Preprint submitted on 10 Feb 2012

HAL is a multi-disciplinary open access archive for the deposit and dissemination of scientific research documents, whether they are published or not. The documents may come from teaching and research institutions in France or abroad, or from public or private research centers.
L'archive ouverte pluridisciplinaire HAL, est destinée au dépôt et à la diffusion de documents scientifiques de niveau recherche, publiés ou non, émanant des établissements d'enseignement et de recherche français ou étrangers, des laboratoires publics ou privés. 
The Exploitation of Fine Phonetic Detail in the Processing of L2 French

Ellenor M. Shoemaker

The University of Texas at Austin

Author Information

Department of French and Italian, B7600, Austin, TX 78712

Email: ellishoe@gmail.com

512-471-5531 (ph) / 512-471-8492 (fax) 


\begin{abstract}
French is a language that poses particular difficulties for the second language (L2) learner in the processing of continuous speech. The phonological processes of liaison and enchainement (resyllabification), can render syllable and word boundaries ambiguous (e.g., un air 'a melody'

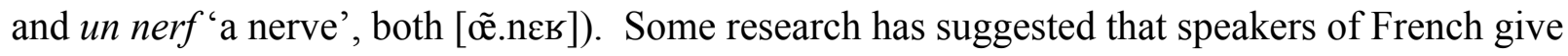
listeners acoustic cues to word boundaries by varying the duration of liaison and initial consonants and that access to mental representations in the lexicon is facilitated by these cues (e.g., Spinelli, McQueen, \& Cutler, 2003); however no study to date has directly demonstrated that durational differences are exploited in the online segmentation of speech.
\end{abstract}

One way to directly test the exploitation of duration as a parsing cue by both native and non-native speakers is to manipulate and exaggerate this single acoustic factor while holding all other factors constant. To this end, the current study employed ambiguous French phrases in which the pivotal consonants (i.e. the /n/ in un air/nerf) had been instrumentally shortened and lengthened while the rest of the phrase remained unaltered. Eighteen native speakers of French and 18 advanced late learners of L2 French were tested on an AX discrimination task and a forced-choice identification task employing these manipulated stimuli. The results suggest that duration alone can indeed modulate the lexical interpretation of sequences rendered ambiguous by liaison in spoken French. In addition, although a good deal of variance was observed in both participant groups, five out of 18 non-native participants scored at or above the native mean on both perceptual tasks. These results are particularly interesting in that they suggest that not only 
can advanced L2 learners develop native-like sensitivity to non-contrastive phonological variation in a L2, but that these learners can exploit this information in L2 speech processing. 
A fundamental aspect of human language is the listener's ability to recognize discrete lexical items in a continuous stream of speech. Currently accepted models of spoken word recognition such as TRACE (McClelland \& Elman, 1986) and Shortlist (Norris, 1994) propose a competition-based recognition system in which a set of candidate words consistent with acoustic (bottom-up) cues are simultaneously activated in the listener's mental lexicon as the input is processed in real time. Activated candidates then compete with one another until the phonemic input eventually reaches the 'divergence point' and a winner is selected. For example, according to these models, when a listener hears the sequence [œ̃n $\tilde{\varepsilon} . .$.$] in French, all phrases that begin$ with this sequence (e.g., un nain, un inconnu, un invalide,...) are simultaneously activated. As

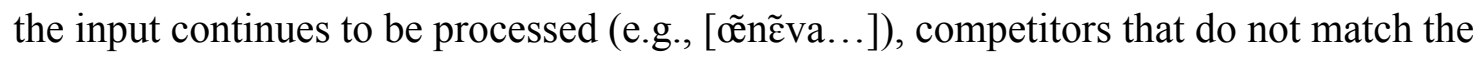
continuing input fall out of competition. The competition process concludes when an optimal parse is achieved and the acoustic signal is segmented into non-overlapping words.

Complicating this process, however, is the fact that speech sounds attach to one another without pause in a continuous acoustic signal; there is no reliable acoustic equivalent of gaps between words as exist in written texts (Lehiste, 1972; Nakatani \& Dukes, 1977). Therefore, listeners must employ perceptual strategies in order to identify where one word ends and another begins in a continuous stream of speech. A substantial body of research has established that acoustic and phonological cues to speech segmentation are not exploited to the same extent and in the same manner cross-linguistically (Cutler, Mehler, Norris, \& Segui, 1989; Cutler \& Norris, 1988; Pallier, Sebastian-Galles, Felguera, Christophe, \& Mehler, 1993; Sebastian-Galles, 
Dupoux, Segui, \& Mehler, 1992; Tabossi, Collina, Mazzetti, \& Zoppello, 2000). Segmentation cues differ from language to language and are thus assumed to pose problems for the segmentation of a L2. Thus while native segmentation strategies render speech perception in one's first language (L1) automatic and effortless, the ease of L1 speech processing stands in sharp contrast to the conscious effort that can be required in the aural comprehension of a L2. Research dealing with specific cues to speech segmentation such as phonotactics (Weber, 2001) and prosody (Cutler et al., 1989; Dupoux, Pallier, Sebastián-Gallés, \& Mehler, 1997) has suggested that L2 learners are constrained by L1 segmentation routines. Therefore, paradoxically, the very segmentation strategies that render the comprehension of our native language so efficient can hinder the processing of a L2 (Carroll, 2001).

Research on the notion of a critical period for language learning has attributed the discrepancy between native and non-native language processing to a post-critical period pruning of phonological sensitivity that leads to perceptual deficiencies for those who undertake the study of a L2 later in life. Many researchers hold that this decline in sensitivity leads to a perceptual foreign accent (Strange, 1995) that leaves late learners with possibly insurmountable deficits in the perception of L2 phonological systems (for a review of research on non-native listening see Cutler 2001, 2002). However, more recent research has suggested that learners can not only suppress the use of L1 segmentation strategies in the processing of an L2 (Cutler, McQueen, \& Suomi, 1997), but can acquire and implement L2 segmentation routines as well (Golato, 2002), challenging strong claims of limitations on the plasticity of phonological learning and perceptual processing in adult learners.

\section{The Processing of L2 French}


The current study examines the exploitation of fine-grained acoustic detail as a segmentation cue by adult learners in the processing of L2 French. French is a language that poses particular challenges for the L2 learner in real time aural comprehension. Lexical ambiguities arise in spoken French as syllable and word boundaries often mismatch due to the processes of external sandhi, liaison and enchaînement, or resyllabification. These processes serve both to avoid hiatus at the boundary between two words (henceforth $\mathrm{W}_{1}$ and $\mathrm{W}_{2}$ ) and to preserve an open syllable structure when possible. Enchaînement occurs when $\mathrm{W}_{1}$ is consonantfinal and $\mathrm{W}_{2}$ is vowel-initial. The coda of $\mathrm{W}_{1}$ is resyllabified across the word boundary to become the onset of $\mathrm{W}_{2}$. The phrase une amie 'a friend' (feminine) is thus produced as [y.na.mi] where syllable and word boundaries are mismatched, instead of [yn.a.mi] where boundaries would be aligned. Liaison on the other hand concerns consonants in final position that are represented graphically ${ }^{1}$, but are not realized phonetically when the word is pronounced in isolation or followed by a consonant-initial $\mathrm{W}_{2}$. The latent consonant is realized before a vowelinitial $\mathrm{W}_{2}$ and then resyllabified through enchaînement explained above. For example, the

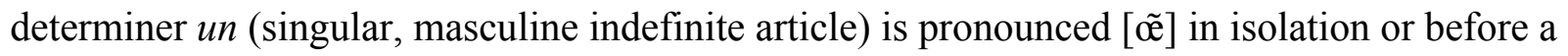
consonant (e.g., un stylo [ã.sti.lo] 'a pen'). When preceding a vowel onset in $\mathrm{W}_{2}$, however, as in un $a m i$ 'a friend' (masculine), the latent /n/ surfaces and is syllabified as the onset of ami.

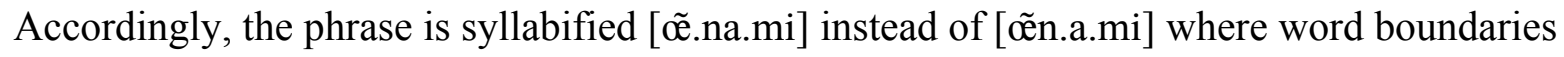
would be respected.

The effects of resyllabification and the misalignment of syllable and word boundaries on the perception of spoken French have generated extensive research (e.g., Gaskell, Spinelli, \&

\footnotetext{
${ }^{1}$ The exception being cases of epenthetic liaison, as in quatre [z] enfants 'four children', where a liaison consonant is introduced spuriously and anomalously in production but does not appear in the orthography of the word.
} 
Meunier, 2002; Nguyen, Wauquier, Lancia, \& Tuller, 2007; Spinelli, McQueen, \& Cutler, 2002, 2003; Yersin-Besson \& Grosjean, 1996 among others), mainly due to a body of work suggesting that the syllable serves as the basic perceptual unit for speech processing in French (Cutler et al., 1989; Mehler, Dommergues, Frauenfelder, \& Segui, 1981). Using a word-spotting task, Dumay, Banel, Frauenfelder and Content (1998) showed that reaction times were significantly faster in identifying the word lac embedded in the non-word ZUN.LAC (where lac is necessarily aligned with a syllable onset due to the fact that $/ \mathrm{nl} /$ is an illicit onset in French), than in ZU.GLAC (where /gl/ is an allowed onset and word and syllable boundaries are therefore not necessarily aligned). According to the authors, these results provide strong evidence that syllable onsets constitute favored points of lexical access in French. However, as Dumay, Content \& Frauenfelder (1999) point out, “one important shortcoming of a syllable-based segmentation strategy is its difficulty in handling potential resyllabification phenomena resulting from phonological processes applying across word boundaries as in the case of French liaison, [in that]... an incorrect lexical alignment would be made on the basis of syllable onsets" (Dumay, Content \& Frauenfelder, 1999, p. 281).

Given the prominent role of the syllable and syllable boundaries in the processing of spoken French, the prevalence of resyllabification would presumably incur severe processing costs and impede speech segmentation processes. However, Spinelli, McQueen, and Cutler (2003) found that in the case of liaison in spoken French, perceptual efficacy and processing in native speakers are not hindered by resyllabification. They probed lexical access processes and revealed significant priming effects for both consonant-initial and vowel-initial words in globally ambiguous sentence pairs such as c'est le dernier rognon, 'it's the last kidney', and c'est le 
dernier oignon, 'it's the last onion', both [se.lə.dєв.nje.во̃.jõ], even though resyllabification renders the two phrases putatively homophonous. This study employed four priming conditions in a lexical-decision task: an ambiguous liaison condition (c'est le dernier oignon), an ambiguous non-liaison condition (c'est le dernier rognon), an unambiguous condition where liaison would not be possible (c'est un demi rognon, 'It's a half kidney'), and finally an unambiguous baseline condition using an unrelated word where liaison would not be possible (c'est un ancien nitrate, 'It's an old nitrate'). Significant priming effects were found for both vowel-initial (oignon) and consonant-initial (rognon) in the ambiguous conditions. In other words, the ambiguity caused by liaison and subsequent resyllabification of the pivotal consonant did not impair the lexical activation of the vowel-initial candidate. Furthermore, priming effects followed the intention of the speaker; that is, priming effects were stronger for oignon than for rognon when the speaker intended oignon, and vice versa. Their results also suggested that words not intended by the speaker in ambiguous contexts (e.g., oignon when dernier rognon is intended) were activated, but not as strongly as in the intended production. Significantly, they did not find priming effects for oignon in an unambiguous condition where liaison is not possible (e.g., demi rognon), suggesting that only the liaison environment allows for the activation of both consonant- and vowel-initial lexical candidates.

The majority of the classical literature on the acoustic-phonetics of French has maintained that consonants are identical at the acoustic level whether they appear as liaison consonants or initial consonants (e.g., Grammont, 1960; Encrevé, 1988), though as early as 1940, Delattre noted that consonants that surface in liaison are plus faibles 'weaker' than the same segment in initial position. More current research has validated Delattre's observation and shown systematic durational differences between consonants that surface in liaison environments 
and their lexical-word-initial counterparts. Dejean de la Bâtie (1993) found that the duration of both the closure and following burst are both shorter for liaison /t/ compared with word-initial /t/. Wauquier-Gravelines (1996) found similar results for /t/, which had an average closure duration of $50 \mathrm{~ms}$ in liaison position and $70 \mathrm{~ms}$ in initial position, though she did not find significant durational differences between liaison and word-initial /n/ (58 ms versus $61 \mathrm{~ms})$. Similarly, Gaskell et al. (2002) also found durational differences. The segments /t/, /s/ and $/ \mathrm{z} /$ were significantly shorter when realized in liaison environments (mean $73 \mathrm{~ms}$ ) than in word-initial position (mean $88 \mathrm{~ms}$ ). Spinelli et al. (2003) found significant durational differences among five consonants that surface in liaison $/ \mathrm{n}, \mathrm{t}, \mathrm{b}, \mathrm{g}, \mathrm{p} /$. LCs were on average $17 \%$ shorter than ICs. Measurements of the pivotal consonants revealed that ICs were on average $10 \mathrm{~ms}$ longer (difference range $=6$ to $12 \mathrm{~ms}$ ) than word-final, resyllabified consonants.

Spinelli et al. (2003) hypothesized that listeners exploit "subtle but reliable" durational cues in French to mark word boundaries and that this durational variation facilitates access to representations in the mental lexicon (p. 248). They suggested that these differences are robust enough to "bias interpretation in the correct direction" (p. 250) in cases of ambiguity, however this suggestion remains conjectural as this study did not directly demonstrate that duration was guiding participants’ responses.

One way to verify the use of duration as a segmentation cue is to manipulate this one acoustic factor in the same physical utterance, while holding all other acoustic factors in the signal constant. To this end, the current study employs both an AX discrimination task and a forced-choice identification task which utilize sequences in which the pivotal consonants in

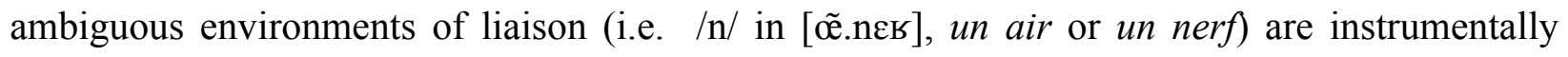


shortened and lengthened while the rest of the utterance remains unaltered. An AX discrimination task is employed to tap lower-level acoustic processing, while a forced-choice identification task is used to investigate the use of segmental duration in higher-level lexical decision processes. In this way it can be determined whether the durational variation of the pivotal consonants represents a sufficient acoustic cue for segmentation.

Furthermore, the current study examines the perceptual capacities of highly advanced adult learners of French, which touches upon an area of research that has received little attention to date - namely, the acquisition and exploitation of within-category allophonic variation in L2 processing. While, the acquisition of L2 phonemic contrasts has generated an extensive body of work (e.g., Best, 1995; Flege, 1995), much less research focus has been placed on the use of noncontrastive phonetic detail the L2.

\section{Method}

\section{Participants}

The control group consisted of 18 native speakers (NS) of French (15 female, 3 male) ranging in age from 19-54 years (mean: 30.2 years). The L2 group consisted of 18 native speakers of English (11 female, 7 male; mean age: 42.2 yrs, range: 26-71) all of whom met a minimum immersion requirement of five years in France or a French-speaking country at the time of testing (mean residency: $13.8 \mathrm{yrs}$; range: 5 - $44 \mathrm{yrs}$ ). Mean age of arrival in France for the non-native speaker (NNS) group was 28.4 years (range 18-59 years). Mean age of first exposure to French (e.g., either through classroom instruction or time spent in a French-speaking country) was 17.2 years of age (range $6-54$ years of age).

\section{Materials}


Of the six consonants that surface in liaison environments in French, /g, n, p, s, t, z/, three, $/ \mathrm{n}, \mathrm{t}, \mathrm{z} /$, were chosen to be investigated in this study for the following two reasons. First, these segments represent three different degrees of obstruence (nasal, plosive and fricative respectively). Second, these three segments were chosen based on frequency. According to the Phonologie du français contemporain corpus, which is based on speech samples from 600 native French speakers from various regions (www.projet-pfc.net; see Durand, Laks \& Lyche, 2005 for a full description of this corpus), these three consonants are the most commonly realized in liaison environments in modern spoken French.

Four vowel-initial words were selected, each preceded by words ending in /n, t, z/, thus triggering liaison and ostensibly homophonous sequences. For example, the word air 'melody'

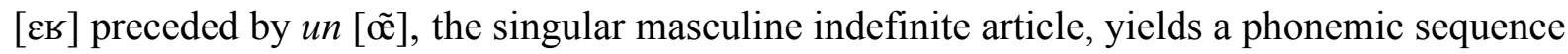

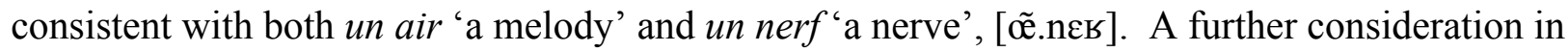
the selection and formation of target pairs was the possible effect of lengthening due to stress placement. Stress accent is fixed (i.e., never lexical) in French and consistently falls on the final syllable of a word in isolation or the final syllable of a phrase. Furthermore, stress in French is most prominently signaled by duration (e.g., Delattre, 1951, 1966). For this reason, there was some concern that the number of syllables of the target word in which the consonant appears could present an additional lengthening factor in the production process. In order to address lengthening, this factor was incorporated into the design of the experiment as an additional independent variable. Half of the target words consisted of one-syllable words and the other half consisted of two-syllable words. This process resulted in a total of 12 pairs of ambiguous phrases (24 target words; see Appendix). 
Six native speakers of French (5 female and 1 male) aged 25-32 years old (mean 27.3 years) recorded 432 sentences including these globally ambiguous phrases. The durations of the three segments under investigation were then analyzed in both liaison position (e.g., /n/ in un air) and initial position (e.g., /n/ in un nerf). All acoustic measurements were made from spectrogram and waveform displays in Praat sound-editing software (Boersma \& Weenink, 2007).

A factorial analysis of variance (ANOVA) revealed that consonants appearing in liaison position (mean $83.44 \mathrm{~ms}$; SD 22.86; henceforth LC) were shorter than consonants appearing in initial position (mean 101.08 ms; SD 24.04; henceforth IC), a difference which was statistically significant: $F(1,428)=60.81, p<.001$. Furthermore, the number of syllables in the word in which the target consonant appeared also affected duration. Consonants in one-syllable words were significantly longer than consonants in two-syllable words: $F(1,426)=51.64, p<.001$.

From this production sample, a set of experimental stimuli to be used in a forced-choice identification task was created by enhancing the durational differences between LCs and ICs through instrumental manipulation. In order to determine which value the duration of the manipulated consonants should take, the distribution of durations from the production sample was examined. Following methodology laid out in Shatzman and McQueen (2006), the factor by which the shortened and lengthened segments were manipulated was the standard deviation (SD) in each respective condition.

Previous behavioral studies employing similar methodologies utilized stimuli whose segments were altered by a fixed factor of duration (e.g., Quené, 1992; Warner, Jongman, Sereno, \& Kemps, 2004). For the current study, it was decided to manipulate the stimuli by a factor of the SD for two reasons. First, given that the objective of the current study is to examine 
the perception of allophonic variation in pivotal consonants, the use of the SD ensures that the durations of manipulated stimuli — although exaggerated — represent points that fall within a reasonable durational distribution and therefore represent viable instances of allophonic variation in spoken French. Second, SDs are calculated for each particular consonant in each condition. The SD factor is therefore more sensitive and context-specific than a fixed durational factor in that it takes into account any possible variation among due to inherent durational differences owing to consonant class.

A three-step durational continuum of stimuli was created which included (1) a shortened consonant representing a LC, (2) a baseline consonant representing durations intermediate to those of LCs and ICs, and (3) and lengthened consonant representing an IC. For each of the three segments, /n, t, z/, six separate measurements were calculated: The shortened (liaison) version of each token represented the mean duration for all instances of that consonant in the liaison environment minus one SD from that particular mean. The value for the midpoint of the continuum (baseline version) represented simply the mean duration across all instances (LCs and ICs) of each consonant. Finally, the value for the lengthened (word-initial) version of the consonant represented the mean duration for that consonant in word-initial position plus one SD from that particular mean. Again, since significant differences were found between the segmental durations of one-syllable and two-syllable words, a different continuum of durations was calculated for each of these conditions. The resultant durations used as target values in the manipulated stimuli are presented in Table 1. Values in parentheses represent the percentage difference from the production mean in that particular condition.

TABLE 1 ABOUT HERE 
Using the target durations calculated in Table 1, tokens were subsequently edited using Praat speech-editing software. The recordings from one of the six speakers who participated in the production procedure were chosen to be manipulated for use in the behavioral tasks. Although recordings were made and measurements were taken of both the vowel-initial and consonant-initial member of each lexically ambiguous minimal pair, only the consonant-initial member of each pair was chosen for the sake of limiting the number of stimuli to be employed in the perceptual portion of the experiment. For example, tokens of both un air and un nerf were recorded and included in the acoustic analyses reported above, only one token of un nerf was chosen to be instrumentally altered.

Durations of $/ \mathrm{t} /$ were manipulated by either deleting a portion of the closure as needed to shorten the consonant or by inserting a segment of silence into the closure as needed to lengthen the consonant. Durations for $/ \mathrm{n} /$ and $/ \mathrm{z} /$ however were manipulated by cross-splicing. Again, following methodology laid out in Shatzman and McQueen (2006), middle portions of /n/ and /z/ were deleted leaving approximately $20 \mathrm{~ms}$ of the initial and final portions of the segment. A portion of a version of the same segment from another version of the same word from the same speaker was then spliced into the recording in order to attain the desired duration. All splices were made at zero crossings in an effort to avoid any acoustic artifacts such as clicks, buzzes or other audible distortions that could occur in the splicing process.

The manipulation of these phrases resulted in 36 sequences (12 phrases x 3 manipulated versions) that are therefore phonemically identical in their content but differ as to the precise acoustic phonetic realization of the individual consonants under investigation. These manipulated stimuli were then utilized in the AX discrimination task and the forced-choice identification task presented below. 


\section{Procedure: Experiment 1 (Ax Discrimination Task)}

An AX discrimination task was employed to investigate the saliency of durational differences by establishing thresholds of noticeability between LCs and ICs for both native speakers (NS) and non-native speakers (NNS) of French. The use of a discrimination task is

motivated by the assumption that segmental duration represents an effective cue to segmentation and lexical access in cases of ambiguity only to the extent that this cue is perceptually salient to listeners.

Stimuli in the AX task consisted of pairs of phrases drawn from the three-step continuum of manipulated sequences described earlier. Each token on the three-step durational continuum was paired with a duplicate version of the same token as well as with the other two manipulated versions of that token on the continuum. This resulted in nine pairings for each of the 12 manipulated phrases (where 1 represents a shortened token, 2 represents a baseline token, and 3 represents a lengthened token). Of the nine stimulus pairs, three were identical $\left(1 \_1,2 \_2,3 \_3\right)$ and six were different $\left(1 \_2,1 \_3,2 \_1,2 \_3,3 \_1,3 \_2\right)$. Of the six different pairs, two pairs were separated by two degrees on the durational continuum $\left(1 \_3,3 \_1\right)$ and four were separated by one degree (1_2, 2_1, 2_3, 3_2).

Participants were tested individually in a quiet room. Based on a body of methodological research which has suggested that it is important for bilingual participants to be in the appropriate language 'mode' while in the experimental environment (e.g., Grosjean, 1998), oral communication at the time of testing was conducted in French with both participant groups. Written instructions concerning the experimental tasks to be performed were also presented in French. The experimental protocol was created using E-Prime experimental software (Schneider, Eschman, \& Zuccolotto, 2002) and presented on a Dell Inspiron 600m laptop 
computer. Stimuli were presented binaurally through Koss UR 20 headphones. Participants were instructed that they would hear pairs of phrases in French and to indicate whether the two phrases were identical or different by pressing on the keyboard either 1 or 2 respectively. No direction was offered to participants as to what parameters responses should be based on. Participants were asked to respond quickly, but not so quickly as to sacrifice accuracy. Before beginning the experiment, participants completed a training portion consisting of 14 trials in order to familiarize them with the procedure. Items included in the training portion were not included in the experimental portion. Each experimental trial consisted of one pair of manipulated stimuli separated by an inter-stimulus interval of $250 \mathrm{~ms}$. Individual trials were separated by a $2000 \mathrm{~ms}$ pause. A response limit was set at $6000 \mathrm{~ms}$. Each of the 9 pairs of 12 stimuli was presented 6 times in random order, resulting in a total of 648 trials. There were no visual stimuli to accompany the auditory stimuli. No feedback as to the accuracy of responses was given in either the training or the experimental portion. Testing lasted approximately 50 minutes.

\section{Results: Experiment 1}

One NNS participant was removed from analysis due to the fact that he responded same to all 648 trials of the experiment. The analyses that follow therefore include 17 NNS participants and $18 \mathrm{NS}$ participants. Responses for the three same pairs $\left(1 \_1,2 \_2,3 \_3\right)$ were not included in the analysis, therefore only responses for the six different pairs $\left(1 \_2,1 \_3,2 \_1,2 \_3\right.$, 3_1, and 3_2) are reported here. All analyses are by subject.

Mean d-prime scores were analyzed as a function of Pair and Participant Group in a twoway ANOVA, the results of which are shown in Table 2. This analysis revealed a main effect for Pair: $F(5,198)=33.32, p<.001$. There was no effect for Participant Group: $F(1,198)$ 
$=.1 .67, p=0.198$. No interaction between the two factors was observed: $F(5,198)=0.24, p=$

0.946. For NS and NNS participants, stimulus pairs separated by two degrees on the durational continuum showed significantly higher discrimination than one-degree differences according to d-prime analysis, indicating that durational differences are perceptually salient only when greatly exaggerated. Pairs separated by one degree were rarely associated with a d-prime score superior to 1 , indicating a lack of discrimination. In addition, there was a great deal of variation across participants in both the NS and NNS groups as evidenced by the substantial standard deviations observed in both participant groups, which suggests the degree of difficulty of the task.

\section{TABLE 2 ABOUT HERE}

Mean D-prime scores for both participant groups were then analyzed as a function of each individual consonant (see Tables 3-5). This combined analysis revealed a main effect for Consonant: $F(2,594)=37.70, p<.001$. An effect for Pair was also observed: $F(5,594)=71.04$, $p<.001$. However, no effect for Participant Group was observed: $F(1,594)=2.55, p=.111$. In addition there was a significant interaction between Pair and Consonant: $F(10,594)=2.916, p=$ 0.001. This interaction suggests that discrimination performance for each participant groups depends on the particular segment. There were no significant interactions between the factors Participant Group and Pair: $F(5,594)=0.64, p=0.669$; Participant Group and Consonant: $F(2$, $594)=0.38, p=0.682$; or Participant Group, Consonant and Pair: $F(10,594)=0.50, p=0.888$.

TABLE 3 ABOUT HERE

TABLE 4 ABOUT HERE

TABLE 5 ABOUT HERE

\section{Discussion: Experiment 1}


The results of Experiment 1 suggest that only stimuli separated by two degrees on the durational continuum are sufficiently different acoustically to be systematically distinguished by both NS and NNS groups. For both participant groups, pairs separated by two degrees on the durational continuum showed significantly higher discrimination than one-degree differences according to d-prime analysis. Pairs separated by one degree showed a lack of consistent discrimination. In addition, there was a great deal of variation across participants in both the NS and NNS groups. This finding suggests that these acoustic differences may not represent a very robust processing cue in natural speech. Furthermore, the large amount of variation among participants in both groups suggests that individual listeners may not make use of this cue in a systematic fashion.

Regarding performance comparisons between the two participant groups, the current results fail to provide conclusive evidence of a difference in sensitivity between NS and NNS participants. The results suggest that the NNS participants are performing at nativelike levels. However, the amount of variation observed in both groups makes it difficult to ascertain whether the lack of significant difference between the two group's performance is attributable to nativelike behavior on the part of the NNS group or to the relatively noisy data obtained from both groups. Support for nativelike behavior on the part of NNS participants comes from the fact that perceptual differences among the three consonants follow the same pattern as NS participants, namely, stimuli containing /n/ were discriminated better than stimuli contained / $/$, which in turn were discriminated better than stimuli containing /z/, indicating that the NNS participants are exploiting to the same acoustic in the signal as the NS participants. Our tentative conclusion is that the NNS are performing in a nativelike manner; however this issue will be revisited for further discussion below. 


\section{Procedure: Experiment 2 (Forced-Choice Identification Task)}

Experiment 2 consisted of a forced-choice identification task also employing manipulated tokens taken from the three-step durational continuum of stimuli described above. While the AX discrimination task is employed to tap lower-level acoustic processing, an identification task is employed to investigate the use of segmental duration in higher-level lexical decision processes. Participants in Experiment 2 were the same as in Experiment 1. Each experimental trial had the following structure. Participants heard one of the three manipulated phrases from the durational continuum presented aurally through headphones. Phrases were presented without a carrier frame, thus eliminating any potential priming effects from context. At the offset of the auditory stimulus, two words appeared on the computer screen. The two visual targets consisted of the Vinitial and C-initial candidates representing the two possible interpretations of each ambiguous sequence described above, for example, when auditory stimulus is a manipulated version of the

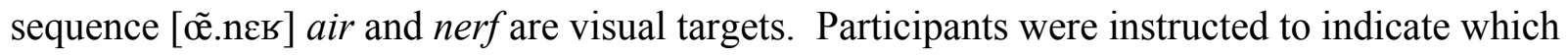

of the two words presented on the screen was present in the phrase they had heard by pressing on the computer keyboard either (1), corresponding to the word on the left of the screen, or (2), corresponding to the word on the right of the screen. There was no delay between the offset of the auditory stimulus and the presentation of the visual targets. Each of the 36 stimuli (i.e. three manipulated versions of each of 12 tokens) was presented randomly six times resulting in a total of 216 trials. Participants completed a training portion consisting of 14 trials before beginning the experimental portion in order to familiarize them with the procedure. Items included in the training portion were not included in the experimental portion. Individual trials were separated by $2000 \mathrm{~ms}$. Visual targets were counter-balanced across participants in order to offset any possible bias toward the left-hand visual target that might occur from reading effects. Half of the 
participants were presented with the $\mathrm{V}$-initial (liaison) target on the left of the screen and the other half were presented with the C-initial target on the left of the screen. Testing lasted approximately 20 minutes.

\section{Results: Experiment 2}

The proportion of V-initial (i.e. 'liaison') responses was calculated for manipulated stimuli in each of the three continuum conditions: the shortened (LC) version, the baseline version, and lengthened (IC) version. A two-way factorial ANOVA compared participant groups and proportions of responses across the three continuum conditions. This analysis revealed a main effect for Continuum Condition: $F(2,102)=74.30, p<.001$. However no significant difference between the two Participant Groups was observed: $F(1,102)=0.73, p=0.393$. There was no interaction between the two factors: $F(2,102)=1.26, p=0.298$. Mean proportions of liaison responses for both NS and NNS participants groups across continuum conditions are given in Table 6 with means, standard deviations, and the results of t-tests comparing mean proportion responses to chance performance $(50 \%)$.

\section{TABLE 6 ABOUT HERE}

The above results suggest that the duration of the pivotal consonant alone can indeed modulate the lexical interpretation of ambiguous sequences for both NS and NNS. Shortened consonants elicited significantly more V-initial responses, while lengthened consonants elicited significantly more $\mathrm{C}$-initial responses. In addition, baseline consonants elicited roughly the same proportion of $\mathrm{V}$-initial and $\mathrm{C}$-initial responses, indicating a guessing strategy on the part of participants due to a lack of sufficient acoustic information in the signal. However, as was observed in the AX discrimination task, there was a great deal of variation across participants in 
both groups as evidenced by the range of responses. This again brings into question the consistency with which this single acoustic cue is exploited in natural speech.

Proportions of $\mathrm{V}$-initial (i.e., liaison) responses were then analyzed as a function of each individual consonant (see Table 7). This combined analysis revealed a main effect for Consonant: $F(2,306)=10.16, p<.001$, as well as a main effect for Continuum Condition: $F(2$, $306)=86.41 p<.001$. No significant difference between the Participant Groups was observed: $F(1,306)=0.01, p=0.921$.

All interactions among the three factors were significant. There was a significant interaction between the factors Participant Group and Consonant: $F(2,306)=6.30, p=0.002$. There was a also significant interaction between the factors Continuum Condition and Consonant: $F(4,306)=12.06, p<.001$, as well as between the factors Participant Group and Condition: $F(2,306)=9.29, p=.001$. In addition a three-way interaction was revealed among all factors: $F(4,306)=3.28, p=.012$. These results suggest that the degree of exploitation of durational differences in the segmentation of speech varies as a function of the particular segment and of continuum condition.

\section{TABLE 7 ABOUT HERE}

\section{Discussion: Experiment 2}

The results of Experiment 2 suggest that the duration of the pivotal consonant in liaison environments can indeed modulate the lexical interpretation of ambiguous sequences. Responses for both participant groups displayed a significant effect of continuum condition; that is both groups chose the V-initial (liaison) target significantly more often when presented with a shortened stimulus and the $\mathrm{C}$-initial target more often when presented with a lengthened stimulus. Crucially, the baseline stimuli — which represent durational values intermediate to 
those of LCs and ICs - elicited roughly the same amount of V-initial and C-initial responses, suggesting a lack of sufficient acoustic information in the signal.

Taken as a whole, the pattern of data from both experiments supports the hypothesis that segmental duration can modulate the lexical interpretation of ambiguous liaison sequences in spoken French. Unlike previous studies, which have hypothesized that duration serves as a cue to disambiguation in environments of liaison, but have not tested this cue directly (Gaskell et al., 2002; Spinelli et al., 2003), the current study has demonstrated an effect of variation in segmental duration by manipulating this factor while all other acoustic factors remain unchanged.

It is worth pointing out again that these durational differences may not represent a consistently robust processing cue in natural speech. However, the fact that both NS and NNS groups responded in the predicted direction demonstrates that segmental duration does have cue value in the processing of liaison environments in spoken French. These results offer strong evidence that durational differences between LCs and ICs are indeed encoded phonologically in the L1 and L2 grammars. Although the particular cue investigated here may not be extremely robust in natural speech, it is nonetheless a part of the L1 and L2 phonological inventory and therefore must be included in any comprehensive model of spoken word recognition.

\section{L2 Processing and Nativelike Performance}

Much work in psycho- and applied linguistics seeks to identify and quantify nativelike behavior on linguistic tasks on the part of non-native participants (i.e. non-native behavior that is indistinguishable from that of native controls). As Birdsong (2009) says, "referencing learner performance to that of natives provides an easily understood metric of the potential for learner attainment" (p. 408). It is important to note, however, that native performance itself is a measure 
that must also be empirically established; it is neither uniform nor predictable. Once native performance has been quantified, nativelike behavior on the part of non-native subjects is usually operationalized in the literature as performance that falls either within the actual range of measurements obtained for native controls, or within 1 standard deviation above and below mean native measurements.

Globally, there was no significant performance difference between the NS and NNS groups in the current study. Our results indicate that the NNS participants in this task are performing in a nativelike manner, suggesting that adult learners of French can develop sensitivity to fine-grained acoustic detail and exploit this detail in lexical access and speech processing.

However, the quantification of nativelike performance in the current investigation is difficult given the degree of variation among the NS participants. This NS variation resulted in large standard deviations on both the discrimination and identification tasks. For this reason, even more stringent measures of nativelikeness than are usually found in the literature have been employed. Nativelike performance is operationalized here as NNS performance that is at or above native means themselves, as opposed to within 1 standard deviation above or below this mean. Table 8 presents mean d-prime scores across different pairs in the AX discrimination task for individual participants in each group. Seven NNS participants showed mean d-prime scores above the native mean of 1.09 . These NNS scores are shaded in grey.

\section{TABLE 8 ABOUT HERE}

Performance on the identification tasks was operationalized as an average of the proportion of $\mathrm{V}$-initial responses for shortened stimuli and the proportion of $\mathrm{C}$-initial responses for lengthened stimuli. Table 9 shows mean NS and NNS response proportions on Experiment 
2. Six NNS participants scored above the native mean of $73.50 \%$. These NNS scores are shaded in grey.

\section{TABLE 9 ABOUT HERE}

Of particular note is that five NNS participants performed above the NS mean across both behavioral tasks. Our results thus suggest that highly advanced learners of L2 French can develop nativelike sensitivity to allophonic durational variation in environments of liaison in spoken French. Perhaps a more provocative finding concerning the performance of L2 participants in the current study is that that non-contrastive phonetic detail in a L2 is acquired at all, let alone to nativelike levels. As noted above, the study of the acquisition of non-native contrasts has received much attention in the literature; however the acquisition of noncontrastive detail, in either L1 or L2, has not been tackled by many researchers (for an exception see Darcy, Peperkamp, \& Dupoux, 2007). Furthermore, this finding raises the question as to how sensitivity to non-contrastive detail is acquired.

\section{Conclusion}

The current study has investigated the perceptual capacities of both native French speakers and adult learners of L2 French in the exploitation of durational differences that arise between segments produced in word-initial position and segments that surface in liaison. The speech signal is characterized by substantial amounts of variation and uneven distributions of acoustic factors. Given the fact that both native and non-native listeners are likely exposed to a distribution of spoken French in which individual tokens of consonants in initial and liaison position may or may not exhibit the durational variation discussed here, the fact that listeners interpret speech in the predicted direction when exposed to manipulated tokens of these segments shows that this particular acoustic detail does indeed have cue value. If this cue were 
not encoded as a phonological rule in listeners' grammars, no effect of duration would be observed in the behavioral tasks employed here.

Of particular note is the fact that several advanced NNS participants showed nativelike sensitivity to durational variation in the interpretation to ambiguous sequences at or above native levels in both behavioral tasks, demonstrating that highly advanced learners can acquire the use of non-contrastive phonetic detail in L2 lexical processing. These results contribute to a growing body of research on the upper limits of L2 phonological processing. Instances of nativelike performance in an L2 have been attested in numerous experimental tasks dealing with L2 domains ranging from morphosyntax (e.g., Birdsong, 1992; Birdsong \& Molis, 2001, MarinovaTodd, 2003) to pronunciation (e.g., Birdsong, 1992, 2003; Bongaerts, 1999, Marinova-Todd, 2003). At present, the current study is among the first to demonstrate nativelike attainment with respect to perceptual sensitivity to fine-grained acoustic detail in the L2.

\section{References}

Best, C. (1995). A direct realist view of cross-language speech perception: New Directions in Research and Theory. In Winifred Strange (ed.) Speech perception and linguistic experience: Theoretical and methodological issues. (pp. 171-204). Baltimore: York Press.

Birdsong, D. (1992). Ultimate attainment in second language acquisition. Language, 68(4), 706755.

Birdsong, D. (2003). Authenticité de prononciation en français L2 chez des apprenants tardifs Anglophones: Analyses segmentales et globales. Acquisition et Interaction en Langue Etrangère, 18, 17-36. 
Birdsong, D. (2009). Age and the end state of second language acquisition. In W. Ritchie \& T. Bhatia (Eds.), The new handbook of second language acquisition. Amsterdam: Elsevier.

Birdsong, D. \& Molis, M. (2001). On the evidence for maturational effects in second language acquisition. Journal of Memory and Language, 44(2), 235-249.

Boersma, P. \& Weenink, D. (2007). Praat: doing phonetics by computer (Version 4.6.36) [Computer program]. Retrieved May 12, 2007 from http://www.praat.org/

Bongaerts, T. (1999). Ultimate attainment in L2 pronunciation: The case of very advanced late L2 learners. In D. Birdsong (Ed.) Second language acquisition and the critical period hypothesis. Mahwah, NJ: Lawrence Erlbaum.

Carroll, S. E. (2001). Input and evidence: The raw material of second language acquisition. Amsterdam: John Benjamins.

Cutler, A., Mehler, J., Norris, D.G. \& Segui, J. (1989). Limits of bilingualism. Nature, 340(6230), 229-230.

Cutler, A., McQueen, J. \& Suomi, K. (1997). Finnish vowel harmony and speech segmentation. Max Planck Institute Annual Report 1997, 9.

Cutler, A. \& Norris, D. (1988). The role of strong syllables in segmentation for lexical access. Journal of Experimental Psychology: Human Perception and Performance, 14(1), $113-$ 121.

Cutler, A. (2001). Listening to a second language through the ears of a first. Interpreting, 5(1), 1-23.

Cutler, A. (2002). Native listeners. European Review, 10(1), 27-41. 
Darcy, I., Peperkamp, S. \& Dupoux, E. (2007). Plasticity in compensation for phonological variation: the case of late second language learners. In J. Cole \& J. Hualde (Eds.) Laboratory Phonology, 9, Mouton de Gruyter, Berlin.

Dejean de la Bâtie, B. (1993). Word boundary ambiguity in spoken French. Unpublished doctoral dissertation. Monash University, Victoria, Australia.

Delattre, P. (1940). Le mot est-il une unité phonétique en français ? Le Français Modeme, 8(1), 47-56.

Delattre, P. (1951). Principes de phonétique française: à l'usage des étudiants anglo-américains. Middlebury, Vermont: Ecole française d'été, 2 ed.

Delattre, P. (1966). Studies in French and comparative phonetics. The Hague: Mouton \& Co.

Dumay, N., Content, A. \& Frauenfelder, U. (1999). Acoustic-phonetic cues to word boundary location: Evidence from word-spotting. Proceedings of the fourteenth international congress of phonetic sciences (pp. 281-284). Berkeley, CA: University of California.

Dumay, N., Banel, M., Frauenfelder, U. \& Content, A. (1998). Le rôle de la syllabe: Segmentation lexicale ou classification? Actes des XXIIème Journées d'Etude sur la Parole, (pp. 33-36). Martigny, Switzerland.

Dupoux, E., Pallier, C., Sebastián-Gallés, N. \& Mehler, J. (1997). A destressing 'deafness' in French? Journal of Memory and Language, 36(3), 406-421.

Durand, J., Laks, B. \& Lyche, C. (2005). Un corpus numérisé pour la phonologie du français. In G. Williams (Ed.), La linguistique de corpus (pp. 205-217). Rennes: Presses Universitaires de Rennes

Encrevé, P. (1988). La liaison avec et sans enchaînement. Paris: le Seuil. 
Flege, J. (1995). Second-language speech learning: Theory, findings, and problems. In W. Strange (Ed.), Speech perception and linguistic experience: Theoretical and methodological issues (pp. 233-273). Timonium, MD: York Press.

Gaskell, G., Spinelli, E. \& Meunier, F. (2002). Perception of Resyllabification in French. Memory and Cognition. 30(5), 798-810.

Golato, P. (2002). Word parsing by late-learning French-English bilinguals. Applied Psycholinguistics, 23(3), 417-446.

Grammont, M. (1960). Traité pratique de prononciation française. Paris: Delagrave.

Grosjean, F. (1998). Studying bilinguals: Methodological and conceptual issues. Bilingualism: Language and Cognition, 1(2), 131-149.

Lehiste, I. (1972). The timing of utterances and linguistic boundaries. Journal of the Acoustical Society of America, 6(2), 2018-2024.

Marinova-Todd, S. (2003). Comprehensive analysis of ultimate attainment in adult second language acquisition. Unpublished doctoral dissertation, Harvard University.

McClelland, J. \& Elman, J. (1986). The TRACE model of speech perception. Cognitive Psychology, 18(1), 1-86

Mehler, J., Dommergues, J.Y., Frauenfelder, U. \& Segui, J. (1981). The syllable's role in speech segmentation. Journal of Verbal Learning and Verbal Behavior, 20(3), 298-305.

Nakatani L. \& Dukes, K. (1977). Locus of Segmental Cues to Word Juncture. Journal of the Acoustical Society of America, 62(3), 714-719.

Nguyen, N., Wauquier, S., Lancia, L. \& Tuller, B. (2007). Detection of liaison consonants in speech processing in French: Experimental data and theoretical implications. In P. 
Prieto, J. Mascaró \& M.-J. Solé (Eds.), Segmental and prosodic issues in Romance phonology (pp. 3-23). Amsterdam: John Benjamins.

Norris, D. (1994). Shortlist: A connectionist model of continuous speech recognition. Cognition, 52(3), 189-234.

Pallier, C., Sebastian-Galles, N., Felguera, T., Christophe, A. \& Mehler, J. (1993). Attentional allocation within the syllabic structure of spoken words. Journal of Memory and Language, 32(3), 373-389.

Quené, H. (1992). Durational cues for word segmentation in Dutch. Journal of Phonetics, $20(3), 331-350$.

Schneider, W., Eschman, A. \& Zuccolotto, A. (2002). E-Prime User's Guide. Pittsburgh: Psychology Software Tools Inc.

Sebastian-Galles, N., Dupoux, E., Segui, J. \& Mehler, J. (1992) Contrasting syllabic effects in Catalan and Spanish: The role of Stress. Journal of Memory and Language, 31(1), 18-32.

Shatzman, K. \& McQueen, J. (2006). Segment duration as a cue to word. boundaries in spoken-word recognition. Perception and Psychophysics. 68(1), 1-16.

Spinelli, E., McQueen, J. \& Cutler, A. (2003). Processing Resyllabified Words in French. Journal of Memory and Language, 48(2), 233-254.

Strange, W. (1995). Cross-language studies of speech perception: A historical review. In Strange, W. (Ed.) Speech perception and linguistic experience: Issues in cross-language speech research. (pp 3-45). Timonium, MD: York Press.

Tabossi, P., Collina, S., Mazzetti, M., \& Zoppello, M. (2000). Syllables in the processing of spoken Italian. Journal of Experimental Psychology: Human Perception and Performance, 26(2), 758-775. 
Wauquier-Gravelines, S. (1996). Organisation phonologique et traitement de la parole continue: Contraintes prosodiques et phonologiques de l'accès lexical. Doctoral dissertation. Université Paris 7.

Warner, N., Jongman, A., Sereno, J. \& Kemps, R. (2004). Incomplete neutralization and other sub-phonemic durational differences in production and perception: Evidence from Dutch. Journal of Phonetics, 32(2), 251-276.

Weber, A. (2001). Language-specific listening: The case of phonetic sequences. Doctoral Dissertation. University of Nijmegen (MPI Series in Psycholinguisitcs, 16.)

Yersin-Besson, C. \& Grosjean, F. (1996). L'effet de l'enchaînement sur la reconnaissance des mots dans la parole continue, L'année Psychologique, 96(1), 9-30.

Table 1

Segmental Durations in Milliseconds Used in the Manipulation of Experimental Stimuli.

\begin{tabular}{|c|c|c|c|c|}
\hline \multicolumn{5}{|c|}{ Continuum } \\
\hline & condition & $/ \mathrm{n} /$ & $/ \mathrm{t} /$ & $\mid z /$ \\
\hline & & 64.83 & 44.88 & 72.82 \\
\hline Two-syllable & Shortened (LC) & $(-21.46 \%)$ & $(-29 \%)$ & $(-18.64 \%)$ \\
\hline \multirow[t]{4}{*}{ tokens } & & 94.04 & 71.08 & 94.97 \\
\hline & Baseline & $(0)$ & $(0)$ & $(0)$ \\
\hline & & 129.20 & 105.14 & 117.17 \\
\hline & Lengthened (IC) & $(+22.43 \%)$ & $(+33.12 \%)$ & $(+14.26 \%)$ \\
\hline
\end{tabular}




\begin{tabular}{lcccc}
\hline One-syllable & Shortened (LC) & $(-21.94 \%)$ & $(-39.24 \%)$ & $(-22.21 \%)$ \\
tokens & & 107.78 & 84.71 & 100.86 \\
& Baseline & $(0)$ & $(0)$ & $(0)$ \\
& & 145.23 & 123.32 & 128.11 \\
& & & & \\
& Lengthened (IC) & $(+22.29 \%)$ & $(+32.15 \%)$ & $(+18.47 \%)$
\end{tabular}

Note. Percentage difference from the production mean in each condition is given in parentheses.

Table 2: D-prime Scores on AX Discrimination Task (Experiment 1).

\begin{tabular}{lrrrrrrr}
\hline Group & \multicolumn{6}{c}{ Pair } \\
\hline \multirow{3}{*}{ NS } & & $1 \_2$ & $1 \_3$ & $2 \_1$ & $2 \_3$ & $3 \_1$ & $3 \_2$ \\
\cline { 2 - 8 } & $M$ & 0.76 & 2.18 & 0.76 & 1.00 & 1.39 & 0.44 \\
& SD & 0.60 & 1.07 & 0.67 & 0.56 & 0.62 & 0.36 \\
\hline NNS & $M$ & 0.52 & 1.87 & 0.62 & 0.84 & 1.37 & 0.31 \\
& SD & 0.34 & 0.69 & 0.42 & 0.51 & 0.82 & 0.47
\end{tabular}

Table 3

Mean D-prime Scores on AX discrimination Task (Experiment 1) for /n/ Stimuli.

\begin{tabular}{lrrrrrrr}
\hline Group & \multicolumn{7}{c}{ Pair } \\
\hline \multirow{3}{*}{ NS } & & 1_2 & $1 \_3$ & $2 \_1$ & $2 \_3$ & $3 \_1$ & $3 \_2$ \\
\cline { 2 - 8 } & $M$ & 1.05 & 3.11 & 1.15 & 1.17 & 2.20 & 0.94 \\
& SD & 0.93 & 1.31 & 0.97 & 0.74 & 1.01 & 0.60 \\
& & & & & & & \\
\hline NNS & $M$ & 0.61 & 2.41 & 1.08 & 0.97 & 2.29 & 0.70 \\
& SD & 0.75 & 1.06 & 0.60 & 0.96 & 1.43 & 1.03 \\
& & & & & & & \\
\hline
\end{tabular}


Table 4

Mean D-prime Scores on AX discrimination Task (Experiment 1) for / $/$ Stimuli.

\begin{tabular}{|c|c|c|c|c|c|c|c|}
\hline \multirow[t]{2}{*}{ Group } & \multicolumn{7}{|c|}{ Pair } \\
\hline & & $1 \_2$ & $1 \_3$ & $2 \_1$ & $2 \_3$ & 3_1 & $3 \_2$ \\
\hline \multirow[t]{2}{*}{ NS } & $M$ & 0.62 & 2.26 & 0.84 & 1.28 & 1.56 & 0.22 \\
\hline & SD & 0.80 & 1.18 & 0.89 & 0.88 & 0.88 & 0.40 \\
\hline \multirow[t]{2}{*}{ NNS } & $M$ & 0.57 & 2.18 & 0.54 & 0.95 & 1.33 & 0.12 \\
\hline & SD & 0.55 & 1.44 & 0.69 & 1.00 & 1.17 & 0.80 \\
\hline
\end{tabular}

Table 5

Mean D-prime Scores on AX discrimination Task (Experiment 1) for /z/Stimuli.

\begin{tabular}{lccccccc}
\hline Group & \multicolumn{7}{c}{ Pair } \\
\hline \multirow{3}{*}{ NS } & & $1 \_2$ & $1 \_3$ & $2 \_1$ & $2 \_3$ & $3 \_1$ & $3 \_2$ \\
\cline { 2 - 8 } & $M$ & 0.69 & 2.06 & 0.25 & 0.64 & 0.87 & -0.03 \\
& SD & 0.62 & 1.00 & 0.63 & 0.49 & 0.65 & 0.42 \\
& & & & & & & \\
\hline NNS & $M$ & 0.28 & 1.58 & 0.28 & 0.64 & 1.06 & 0.04 \\
& SD & 0.68 & 0.93 & 0.63 & 0.73 & 0.89 & 0.65 \\
& & & & & & & \\
\hline
\end{tabular}

Table 6

Proportion of 'Liaison' (Vowel-Initial) Responses in Forced-choice Identification Task (Experiment 2). 


\begin{tabular}{|c|c|c|c|c|}
\hline \multirow[t]{2}{*}{ Group } & & \multicolumn{3}{|c|}{ Continuum condition } \\
\hline & & Shortened & Baseline & Lengthened \\
\hline & & (LC) & & (IC) \\
\hline \multirow[t]{2}{*}{ NS } & $M$ & $69.47 *$ & 47.13 & $22.48 * *$ \\
\hline & SD & 14.63 & 6.33 & 13.57 \\
\hline \multirow[t]{2}{*}{ NNS } & $M$ & $67.13^{*}$ & 48.29 & $30.86 * *$ \\
\hline & SD & 16.62 & 12.69 & 19.63 \\
\hline
\end{tabular}

* Above chance performance $(50 \%)$ at $p<.05$.

** Below chance performance $(50 \%)$ at $p<.05$.

Table 7

Proportion of 'Liaison' (Vowel-Initial) Responses in Forced-choice Identification Task (Experiment 2) for Each Consonant.

\begin{tabular}{|c|c|c|c|c|c|c|c|c|c|c|}
\hline \multirow[t]{3}{*}{ Group } & & \multicolumn{9}{|c|}{ Continuum condition } \\
\hline & & \multicolumn{3}{|c|}{ Shortened (LC) } & \multicolumn{3}{|c|}{ Baseline } & \multicolumn{3}{|c|}{ Lengthened (IC) } \\
\hline & & $/ \mathrm{n} /$ & $/ \mathrm{t} /$ & $|z|$ & $/ \mathrm{n} /$ & $/ \mathrm{t} /$ & $|z|$ & $/ \mathrm{n} /$ & $/ \mathrm{t} /$ & $\mid \mathrm{z} /$ \\
\hline \multirow[t]{2}{*}{ NS } & $M$ & $70.83^{*}$ & $68.29^{*}$ & $59.95 *$ & 53.24 & $44.44 * *$ & 44.51 & $17.11 * *$ & $17.36^{* *}$ & $32.64 * *$ \\
\hline & $\mathrm{SD}$ & 25.36 & 17.28 & 19.08 & 10.16 & 11.43 & 12.96 & 18.17 & 10.33 & 18.65 \\
\hline \multirow[t]{2}{*}{ NNS } & $M$ & $79.17^{*}$ & 57.64 & $25.93 * *$ & 56.48 & $41.51 * *$ & 49.41 & $34.03 * *$ & $25.93 * *$ & $35.42 * *$ \\
\hline & SD & 22.51 & 20.27 & 21.23 & 18.43 & 16.60 & 18.28 & 28.63 & 21.23 & 17.81 \\
\hline
\end{tabular}

* Above chance performance $(50 \%)$ at $p<.05$.

** Below chance performance $(50 \%)$ at $p<.05$. 
Table 8

NS and NNS Mean d-prime Scores Across Six Different Pairs (1_2, 1_3, 2_1, 2_3, 3_1, 3_2) on AX Discrimination Task (Experiment 1).

\begin{tabular}{|c|c|c|c|}
\hline \multicolumn{2}{|c|}{ NS } & \multicolumn{2}{|r|}{ NNS } \\
\hline 1 & 0.94 & 1 & 0.36 \\
\hline 2 & 0.62 & 2 & 0.40 \\
\hline 3 & 0.58 & 3 & 0.79 \\
\hline 4 & 2.33 & 4 & 0.21 \\
\hline 5 & 1.16 & 5 & removed \\
\hline 6 & 0.97 & 6 & 1.36 \\
\hline 7 & 0.21 & 7 & 1.28 \\
\hline 8 & 0.90 & 8 & 1.63 \\
\hline 9 & 1.23 & 9 & 1.42 \\
\hline 10 & 0.68 & 10 & 0.47 \\
\hline 11 & 1.39 & 11 & 1.45 \\
\hline 12 & 1.24 & 12 & 0.86 \\
\hline 13 & 0.76 & 13 & 0.96 \\
\hline 14 & 0.55 & 14 & 1.66 \\
\hline 15 & 0.77 & 15 & 0.95 \\
\hline 16 & 1.74 & 16 & 1.35 \\
\hline 17 & 2.39 & 17 & 1.03 \\
\hline 18 & 1.16 & 18 & 0.57 \\
\hline
\end{tabular}




$\begin{array}{cccc}M & 1.09 & M & 0.98 \\ \mathrm{SD} & 0.58 & \mathrm{SD} & 0.46\end{array}$

Table 9: Mean NS and NNS Response Proportions on Forced-choice Identification Task (Experiment 2).

\begin{tabular}{|c|c|c|c|}
\hline \multicolumn{3}{|c|}{$\mathrm{NS}$} & NNS \\
\hline 1 & 67.36 & 1 & 53.48 \\
\hline 2 & 84.03 & 2 & 60.42 \\
\hline 3 & 69.45 & 3 & 63.19 \\
\hline 4 & 90.97 & 4 & 55.56 \\
\hline 5 & 92.36 & 5 & 55.56 \\
\hline 6 & 83.33 & 6 & 85.42 \\
\hline 7 & 57.64 & 7 & 80.56 \\
\hline 8 & 59.72 & 8 & 67.36 \\
\hline 9 & 76.98 & 9 & 91.67 \\
\hline 10 & 68.06 & 10 & 69.45 \\
\hline 11 & 73.62 & 11 & 79.17 \\
\hline 12 & 76.39 & 12 & 78.48 \\
\hline 13 & 56.95 & 13 & 70.14 \\
\hline 14 & 55.56 & 14 & 77.78 \\
\hline 15 & 66.67 & 15 & 63.20 \\
\hline 16 & 59.03 & 16 & 71.53 \\
\hline
\end{tabular}




$\begin{array}{cccc}17 & 92.52 & 17 & 34.72 \\ 18 & 92.31 & 18 & 68.75 \\ M & 73.50 & M & 68.13 \\ \text { SD } & 13.24 & \text { SD } & 13.51\end{array}$

Appendix

Stimuli Used in Experiments 1 and 2

\begin{tabular}{|c|c|c|c|}
\hline Consonant & $\begin{array}{l}\text { Vowel-initial } \\
\text { (liaison) target }\end{array}$ & $\begin{array}{c}\text { Consonant-initial } \\
\text { target }\end{array}$ & Pronunciation \\
\hline \multirow{8}{*}{$/ \mathrm{n} /$} & un hectare & un nectar & [о̃.nck.taь] \\
\hline & 'a hectare' & 'a nectar' & \\
\hline & un aval & un naval & [ã.na.val] \\
\hline & 'a support' & 'a naval officer' & \\
\hline & un air & un nerf & 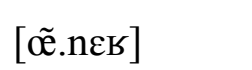 \\
\hline & 'a melody' & 'a nerve' & \\
\hline & un ouf & un neuf & [ã.nœf] \\
\hline & 'an egg' & 'a nine' & \\
\hline \multirow{5}{*}{$/ \mathrm{t} /$} & un grand assaut & un grand tasseau & [õ..grã.ta.so] \\
\hline & 'a big assault' & 'a big bracket' & \\
\hline & un grand ami & un grand tamis & [œ̃.grã.ta.mi] \\
\hline & 'a great friend' & 'a big sieve' & \\
\hline & le grand Est & le grand test & [lə.gচã.test] \\
\hline
\end{tabular}




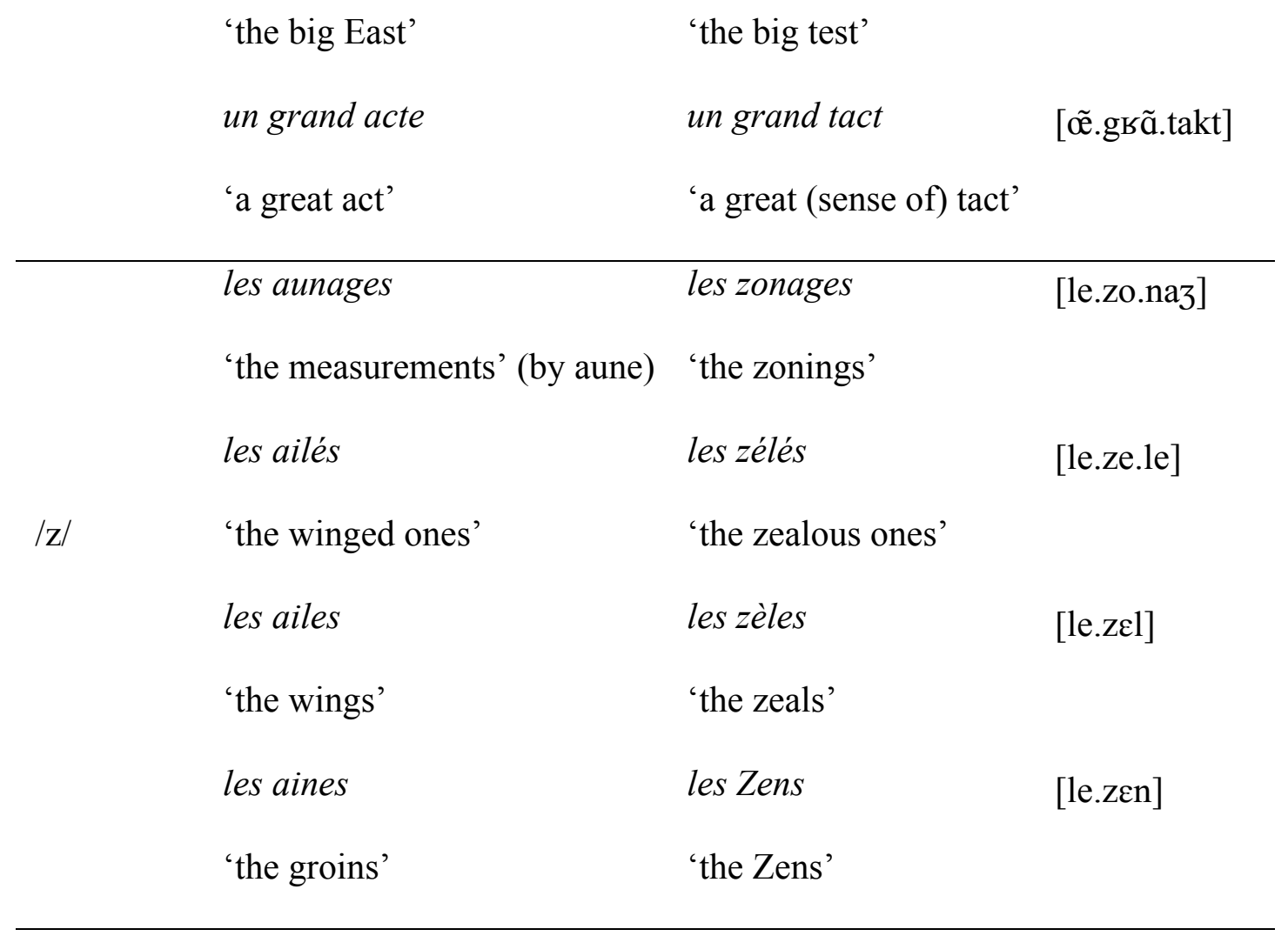

